\title{
Learning Dance Through Art Education in the Era of Hyperreality at Jumapolo 2 State Middle School
}

\author{
Dian Dwiyani Argha Dewi, S.Sn ${ }^{1}$ \\ ${ }^{1}$ SMPN 1 Tasikmadu (Tasik Madu 1 State Middle School) \\ *Corresponding author.Email: diansutoyo3@gmail.com
}

\begin{abstract}
The purpose of art education is basically to develop the sensitivity of students' sensory perceptions through various creative experiences in the art according to the character and developmental stages of artistic abilities at each level of education, as well as stimulating the growth of imaginative ideas so that students have the ability to find various creative ideas in solving. The development of technology at the end of the 20th century has changed the face of the world with the sophistication of IT such as television, films, games, virtual reality, digital photos, and the internet so that in this situation, the development of digital technology has brought human fantasies across borders, creating spaces about various objects. It reaches a stage where visual reality has been transcended by manipulating visual imagery so that it is as if humans are stepping from the real world to a fantasy world, a virtual world that looks real.
\end{abstract}

Keywords: Learning Methods for Dance, Hyperreality, Visual Reality

\section{INTRODUCTION}

\subsection{Background}

The Jumapolo 2 State Middle School is a state middle school within a suburb in the Karanganyar district. The majority of students studying at the school received less attention from their parents, because on average, parents migrated out of town, and some even have left Java to make a living. Besides, the students were living in remote areas where motor vehicles were scarce or they had difficulty in accessing transportation, so they get a dispensation from the police to ride a motorbike to school. Seeing this condition, it is not surprising that most students' academic performances are far from the standard. They would spend more time at home with activities that are less beneficial and were affected by an environment that did not support students' conditions so that automatically they lacked awareness of the importance of learning for their future. To change this condition, the school has a vision: to form human resources who are intelligent, skilled, noble, and environmentally friendly, with the aim of later students having a creative and innovative spirit. However, in reality, these ideal conditions were still not as expected. The experience as a cultural arts teacher who also gets an additional assignment as a class representative has been a valuable experience for the writer to try to approach students and change their character into being independent and confident people through cultural arts learning.

Other problems that often arose in the teaching and learning process in class include the very low level of discipline of students and there were still students who attended the first session late. There were those who frequently skipped school without notice and students were also not on time in submitting school assignments. They had a very poor sense of responsibility and even tended to ignore lessons, especially in the subject of arts and culture. By using learning materials related to making floor patterns or dance composition, it was hoped that there would be improvement in learning, in terms of creativity and innovation of students.

\subsection{Problem Formulation}

After examining the background of the research, the following is the primary problem formulation: How could the researcher find strategies that are effective, efficient, innovative, and fun in the teaching and learning process in the 
classroom to improve the ability to play using floor patterns by throwing a ball to foster a positive culture and be able to shape the character of students?

\subsection{Research Objectives}

The main objectives of this study were:

1. Helping students to understand the meaning of strategies that are effective, efficient, innovative, and fun in learning to dance through dance floor pattern materials

2. Increasing creativity in finding or exploring various forms of dance floor patterns by throwing a ball

3. Fostering a sense of tolerance and acceptance of the diversity of ideas or ideas between students

\section{LITERATURE REVIEW}

\subsection{Dance Education}

Learning refers to a process of gaining knowledge and experience in the form of changes in behavior and the ability to react relatively permanently or permanently due to individual interactions with their environment [1]. Learning is the interaction between teachers and one or more individuals to learn and plan to develop knowledge, skills, and learning experiences for students [2]. According to [3], the art of dance is rhythmic movements partially or entirely of the body consisting of individual or group patterns accompanied by certain expressions or ideas.

\subsection{Art Education in the Hyperreal Era}

Art education is described by [4] as a discipline-based art education that aims to offer systematic and sustainable learning programs in four fields in the art world, namely the fields of creation, enjoyment, understanding, and assessment. These four fields must be reflected in the curriculum. The hyperreality era here is described by [5] as an era marked by the disappearance of markers and metaphysics of representation, the collapse of ideology, and the collapse of reality itself. Hyperreality happens because of nostalgia and fantasy duplication, which has become a substitute reality, adoration of objects that are not visible and no longer objects with representations. It is a time of ecstasy, denial, and annihilation of preexisting habits.

\section{RESEARCH METHOD}

The Creative-Productive-based Cooperative Method is the appropriate learning method to improve students' learning in participating in floor patterns games by throwing a ball in learning cultural arts, specifically dance at Jumapolo 2 State Middle School. This method is a form of learning in groups or teamwork that trains students to work together and respect each other so that a solid team will be formed. Educators are interested in bringing up cooperative methods that are collaborated with creative-productive strategies to explore students' potential and abilities in playing floor patterns by throwing balls and shaping their characters through cultural arts lessons, especially dance, especially on floor pattern material or dance composition. Creativity and productivity are interrelated because learning is ideal if it is developed simultaneously and the students feel happy.

\section{DISCUSSION}

The researcher's teaching experience, which spans almost 19 years, has opened the researcher's eyes in carrying out the profession as an educator. The researcher has observed students' condition whose interest in learning has decreased due to the influence of social media developments and social interactions in society. There are also differences in students' character that make their students' quality different so that teaching becomes an interesting and challenging profession. A teacher must always look for different innovations to adapt to the needs and developments of the times in developing the potential of students in the teaching and learning process in the classroom.

Developing students' potential to become intelligent, skilled, noble, and environmentally friendly human beings following the vision of Jumapolo 2 State Middle School has not been an easy feat. The cooperative method based on Creative-Productive strategies was chosen as a learning model developed concerning various learning approaches to improve the teaching and learning process quality.

The cooperative method is a learning model in which students complete their tasks in groups. Each student works together and helps each other to understand a learning material. This method is very relevant to the scientific approach in the 2013 curriculum, which includes observing, asking questions, reasoning, and trying/exploring the material provided by the teacher. In applying this method, the teacher's role is not limited to bing the only source in the teaching process, but the teacher is also a mediator and manager of learning activities. These steps are taken so that when the learning process takes place, an atmosphere full of openness and democracy will be created and will ultimately provide optimal opportunities for students to obtain more information about the material being taught. Besides, the students' social attitudes and skills will be trained, and they can apply them in their life in society.

Creativity is directly related to productivity and is an essential part of solving problems related 
to increasing students' ability to master floor pattern games material or dance composition. This method is very appropriate to increase creativity that is still not developed, and specific ways are needed to increase students' abilities and creativity. The steps taken include teaching how to develop as many ideas as possible, developing ideas based on other people's ideas, avoiding giving criticism during idea development, evaluating existing ideas, and concluding the best ideas.

These methods are carried out continuously to foster a habit of productive thinking marked by; the ability to think and learn regularly independently, the existence of a critical attitude, and a creative attitude in thinking and learning.

The cooperative method which is combined with productive, creative strategies has the following characteristics:

1. Positive interdependence interaction in learning (reciprocal relationship) where the teacher tries to foster the feelings of students so that they are integrated into groups. Teachers would make sure that all students in one team get the same appreciation, arrange the division of tasks given so that each student in one team gets a part of all the group assignments. Thus, they will support each other, relate, complement, and bond with the group.

2. Face-to-face interaction (interaction between students). Here, the teacher's task is to encourage students to meet face to face, so that processing information creates an effective and efficient atmosphere. It is hoped that they will help each other, remind, provide information, trust, establish communication and motivate group members.

3. Personal responsibility of group members. Encouraging students to have personal responsibility is intended so that teachers can instill a sense in students that personal responsibility is the key to ensuring integrity and strengthening the team in joint learning activities.

4. It requires flexibility in the group concerning interpersonal skills, namely communication between members, where the teacher instills in students to know each other, trust, communicate accurately (not ambitious), accept, support, and resolve conflicts that may occur within the group.

5. Group workflow. In this case, the teacher has the task of assessing the results of the stages of the process carried out by students with their groups. This step aims to increase each team's effectiveness in contributing to collaborative activities that occur during discussions.

In detail, the following are the steps or procedures in applying the cooperative method based on the CreativeProductive strategy that is reflected in the classroom learning scenario:

\section{a. Open (opening)}

At this stage, the teacher communicates the objectives, material, time, learning steps, the expected final results from students, and the assessments that will be carried out. This learning stage is usually carried out during the first meeting during the opening or apperception. In this opening stage, students are given the opportunity to openly express their opinions about the steps and methods to be taken until the final assessment to obtain a two-way agreement. Each class at this stage must have a clear concept of the work to be displayed.

\section{b. Affection}

The learning stage that emphasizes affection is an important stage of the cooperative method with creativeproductive strategies. Students begin to do teamwork in various ways, namely looking for references and making observations through video shows, conducting experiments, and practicing with their groups in a pleasant atmosphere. This stage is the determining stage for the success of a process of creating art. The children's character will be seen and formed directly. Through artistic activities with group work, an attitude of cooperation will be formed based on a sense of compassion.

\section{b. Free (Freedom in exploring the topic)}

This stage is the most enjoyable step to do because the results of exploration or experiment are then analyzed together, discussed, and then the students can experiment again. This stage is carried out in full cooperation without any pressure, but in fact, students are invited to think at high levels (analysis, synthesis, and evaluation) so that they will get used to solving problems or obstacles faced with an unyielding attitude. This stage is carried out face-to-face, although when exploring topics, students can do it outside structured hours. Each student is expected to present their artwork in front of the class, and then their friends respond. At the end of this stage, all students are expected to understand the concept/topic/problem being studied.

\section{d. Protect}

At this stage, students individually and in groups are obliged to protect each other against a product or work that is presented and displayed in the final performance if they get criticism or suggestions from other groups. This stage is performed so that learning will be more meaningful because students have learned a lot to understand and feel the meaning of group unity and integrity. At this stage, there is an interaction between students, students and teachers, as well as students and direct learning media. The peer tutoring process also takes place at this stage. At this stage, the teacher has provided an assessment of the process for each group and their teamwork.

\section{e. Evaluation}

Evaluation is carried out during the learning process and at the end of the lesson. During the evaluation 
process, the teacher observes the attitudes and thinking abilities of students. The aspects that are assessed during the learning process are the seriousness of doing the task, the results of exploration, the ability to think critically, and the ability to think logically in giving views and cooperate and take responsibility. The final evaluation of learning is carried out by giving value to the creative products produced. During these actual exhibitions and performances, students are tested for their ability to cooperate and are required to have more responsibility, tolerance, and strong discipline. Without these traits, it is difficult to achieve success in running a program.

\section{A. Effects of Creative-Productive-based Cooperative Method on Students' Learning}

The impacts of using cooperative methods based on creative-productive strategies on learning include: learning became more meaningful and fun, and children became more enthusiastic and motivated in learning in the classroom. The ability to play floor patterns by throwing balls at students also increased. With the creative-productive learning strategy, students better understood cultural art, especially when learning the application of floor pattern games. There were improved learning outcomes from the affective, cognitive, psychomotor aspects, and the ability to play floor pattern games increased. Student learning outcomes increase and reach a score above the standard grade of around $80 \%$.

1. The students experienced more pleasant learning. Students could pour creative ideas freely through learning dance by throwing the ball without feeling pressured or forced during the learning process. Motivation to attend class was high, so that lateness was reduced. Increasing motivation also improved learning outcomes. This approach could also increase creativity. By working on the application of floor patterns using the ball property as a medium, students were allowed to develop creativity due to group work modifications. They were free to actualize their ideas and wants so that productivity was enabled.

2. Cooperative method based on the creativeproductive strategy could increase cooperation, discipline, responsibility, and empathy among students. By carrying out exploration activities to play using the ball together, students became more enthusiastic in learning dance, were more creative, and developed positive attitudes, including cooperation and responsibility. Besides, this method enabled teachers to teach students to be compassionate towards their surrounding environment and educate children to love one another and sympathize with others' suffering.

\section{B. Supporting Factors}

Supporting factors were provided for implementing cooperative methods with this creative-productive strategy, including:
1. There was full support from the principal for permission to carry out lessons using this approach.

2. Students' enthusiasm and motivation were improved because they could learn and play in a fun atmosphere.

3. Teachers were able to prime the class, which led to students being more enthusiastic about learning dance materials and more responsible for completing group assignments.

\section{CONCLUSION}

The Cooperative Method based on the creativeproductive strategy includes the following procedures: a) Open, b) Affection, c) Free, d) Protect, and e) Evaluate.

1. The survey revealed that $80 \%$ strongly agreed that the Creative-Productive-based Cooperative Method could improve the ability to play using floor patterns by throwing the ball in learning cultural art at Jumapolo 2 State Middle School. Their creativity was directly related to productivity and has shown to improve students' ability to play using floor patterns by throwing a ball

2. The effects of implementing the CreativeProductive-based Cooperative method in learning arts and culture at Jumapolo 2 State Middle School is:

a. With Productive Creative learning strategies, students understood the concept of learning Cultural Arts better, especially about applying floor patterns to traditional dance.

b. The Creative-Productive-based Cooperative Method could enhance students' cooperation, discipline, responsibility, and compassion with a fun learning process that is a playful atmosphere.

\section{REFERENCES}

[1] Sugihartono, dkk. "Psiklogi Pendidikan [Educational Psychology].” Yogyakarta: UNY Press, 2007.

[2] Anwar, "Peta Konsep Untuk Belajar Bermakna [Concept Map for Meaningful Learning].”, 2010. http. bioedu.warbioedu.blogspot.com. Diakses 24 April 2013

[3] sedyawati, E., \& Parani, Y., "Ensiklopedi tari Indonesia. [Indonesian dance encyclopedia.]." Direktorat Jenderal Kebudayaan, Direktorat Sejarah dan Nilai Tradisional, Proyek Pengkajian dan Pembinaan Nilai-nilai Budaya, 1990.

[4] Eisner, E. W., Structure and Magic in Disciplinebased Art Education. Journal of Art and Design Education, $\quad 7(2) \quad$ (1988) $\quad$ 185-96. https://eric.ed.gov/?id=EJ376903

[5] Jean Paul Budrilliard. "Berahi [Lust]." Yogyakarta 1979. 